\title{
ANSELMO E KANT: EMBATES SOBRE O ARGUMENTO ONTOLÓGICO
}

\author{
Joseilson Paixão de Souza ${ }^{1}$
}

RESUMO: A noção de deuses, de forças superiores, sobrenaturais ou mesmo a concepção cristã-ocidental de Deus, talvez seja a mais comum, mais também a mais problemática do ponto de vista filosófico. Para o crente, uma noção mais ou menos fundamental e dada por certa como a de um ser superior existente, representa para o descrente, na forma ateísta, por exemplo, noção amplamente controversa e, por isso, rejeitada por este, justamente por não se mostrar de modo claro, rejeição que, por sua vez, não torna a questão menos problemática. Desde há muito, ou talvez sempre, o conceito de Deus e seus correlatos, ser supremo, causa última, criador, etc. foram objeto de reflexão na história de filosofia.

Palavras-chave: Anselmo; Argumento Ontológico; Fé; Razão.

\section{Considerações iniciais}

$\mathrm{Na}$ filosofia medieval, conceitos como o de Deus fora tratado de modo peculiar. A fé e sua relação com a razão, foram pressupostos fundamentais dentro dos debates filosóficos da época, incluído nestes, uma obra escrita entre 1076 e 1077 por Anselmo de Cantuária (10331109) ou Santo Anselmo, obra na qual contém um texto que ficou conhecido como argumento ontológico. O outro filósofo que tratou do tema da existência de Deus e do argumento ontológico, foi Immanuel Kant 1724-1804). Filósofo Alemão do século XVII que tomou uma posição distinta da de Anselmo, apontando, o que para ele, seriam falhas no argumento. O contexto filosófico de Anselmo gira em torno da questão entre razão e fé, ou entre os limites da autoridade de cada uma destas. Porém, conforme a lógica, o filósofo poderia se servir dela sem reservas.

De modo geral, para um filósofo cristão, uma vez admitido a autoridade da tradição, a razão poderia ser tomada como tendo papel fundamental sem reservas, até mesmo na explicitação dos conteúdos da fé. Poder-se-ia dizer que nesse período haveria uma mensagem cristã que diante da razão estaria em situação de oposição, de independência entre si ou ainda quando a razão não representava para a mensagem cristã nem oposição nem independência mais instrumento natural necessário para mostrar as verdades cristãs. Os escritos de Anselmo como um todo, se dão numa perspectiva da relação entre razão e fé. Anselmo, via na razão natural

\footnotetext{
${ }^{1}$ Graduando do Curso de Filosofia do Campos de Juazeiro da Universidade Federal do Piaui -UFPI; jsousalogus@hotmail.com
} 
instrumento por excelência para falar de Deus. Portanto, não seria o caso de superar uma pela outra. Vasconcellos (2014) explica isto dizendo que "Anselmo não entende a razão como impedimento, nem como alternativa à fé, mas como outro meio de acesso ao conteúdo da revelação (...)" (VASCONCELLOS, 2014, P. 58,). Do mesmo modo, o Proslogio, texto no qual se inclui o seu argumento ontológico sobre a existência de Deus, dá-se grosso modo, a partir deste contexto. Para Vasconcelos (2014), é necessário acrescentar ainda que a existência de Deus é uma verdade que está acessível à razão, e que o propósito último do argumento não seria provar a existência de Deus, mais mostrar sua "razoabilidade". Para Anselmo, existe uma noção, uma ideia de Deus que é comum a todo indivíduo e, ao mesmo tempo, por consequência, seria a mais apropriada definição de Deus: "Deus é o ser do qual nada maior se pode pensar". A partir desse pressuposto ele desenvolve sua argumentação. Assim, diz Anselmo no início do Proslógio:

Então, ô Senhor, tu que nos concedeste a razão em defesa da fé, faze com que eu conheça, até quando me é possível, que tu existes assim como acreditamos, e que és aquilo que acreditamos. Cremos, pois, como firmeza, que és um ser do qual não é possível pensar nada maior. Ou será que um ser assim não existe porque "o incipiente, disse em seu coração: Deus não existe"? Porém, o incipiente, quando eu digo: "o ser do qual não se pode pensar nada maior", ouve o que digo e o compreende. Ora, aquilo que ele compreende se encontra em sua inteligência, ainda que não possa compreender que exista realmente (ANSELMO, 1973, P. 108).

Essa ideia de Deus, portanto, segundo Anselmo, estaria na mente de todos. E esta ideia seria aquela de um Deus todo poderoso, sábio, bondoso etc. De modo que, quando alguém pensa em Deus, o concebe com tais atributos, não sendo possível pensar nele de outro modo. Mesmo no caso de quem o nega, seria obrigado, por assim dizer, a admitir esse pré-requisito. Desse modo, mesmo o ateu convicto, ao negar Deus, o Deus que afirma não existir é este mesmo Deus com tais e tais atributos. Anselmo acredita ter neste pré-requisito outro passo fundamental na argumentação. Deus estaria na mente de todos os homens, até mesmo dos que o negam. Mas até aqui, se está afirmando que Deus estaria apenas na mente e ainda, mesmo um ateu poderia replicar dizendo que a ideia de Deus em sua mente, sendo ela comum também a todos mas, porém, sendo negada positivamente por ele (pelo ateu) quanto a existência de Deus fora da mente, enfraquece ainda mais a defesa da existência do mesmo Deus.

Se se tomar que a ideia de um ser divino como experiência individual é da ordem da subjetividade, ainda assim a questão ficaria em aberto, pois o problema seria exatamente o da comunicação, pois que, não só no contexto de Santo Anselmo como em outros, do ponto vista filosófico, a experiência com o ser divino não se justificou por ser experiência subjetiva. Admitindo o conceito de Anselmo de Deus como aquele do qual não é possível pensar nada maior, com seus atributos, poder, sabedoria, bondade etc. para que isso seja levado a cabo então, 
Deus teria que existir também na realidade. Por que? Por que se Ele existisse somente na mente, haveria, de certo modo, uma limitação nesta ideia de Deus, quando de fato a grande questão é justamente sua existência na realidade. Diz Anselmo (1963, 108): “Mas o ser do qual não é possível pensar nada maior' não pode existir somente na mente”. Existir na mente e na realidade representaria, por assim dizer, existência mais efetiva que somente na mente. Por consequência, se existisse apenas na mente, não seria o Ser do qual não possível pensar nada maior. E conclui Anselmo: "logo, 'O ser do qual não é possível pensar nada maior existe, sem dúvida, na mente e na realidade" (1963, 108), Deus, portanto, existe, seus atributos, entre eles o da existência, lhe acompanham necessariamente.

\section{Objeções e críticas as objeções}

As objeções ao argumento ontológico dadas por Kant (2005), na Crítica da Razaão Pura, publicada em 1781 no capítulo intitulado "Dialética Transcendental", seção IV, se referiram a versão cartesiana do argumento, porém, sendo em seu núcleo básico igual ao argumento de Anselmo. Nas Meditações encontra-se o seguinte texto:

\footnotetext{
Mas, não obstante, quando penso nisso com maior atenção, verifico claramente que a existência não pode ser separada da essência de Deus, tanto quanto da essência de um triângulo retilíneo não pode ser separada da grandeza de seus três ângulos iguais a dois retos ou, da ideia de uma montanha, a ideia de um vale; de sorte que não sinto menos repugnância em conceber um Deus (isto é, um ser soberanamente perfeito) ao qual falte existência (isto é, ao qual falte alguma perfeição), do que em conceber uma montanha que não tenha vale. (DESCARTES apud MENDELI, 2013, p. 33).
}

Portanto, tanto quanto para Anselmo (1965), para Descartes não é possível conceber Deus sem o atributo da existência. Ambas objeções de Kant (2005), analisam o valor lógico da proposição e, por consequência, sua legitimidade. Para os termos da crítica Kantiana colocar-se-á o argumento ontológico, anselmiano e cartesiano, do seguinte modo: Deus é ser perfeitíssimo, portanto ele existe. Assim, para que ele seja Deus perfeito deve existir necessariamente. Desse modo sua existência estaria contida no seu conceito (pois, conforme Anselmo, este conceito é necessariamente acompanhado dos seus atributos, entre eles, o da existência).

Um dos caminhos que Kant (2005) segue é o de questionar esta passagem da concepção mental do conceito de Deus para sua existência real. Para ele, a existência, assim como outros atributos (predicados) realmente acompanham o conceito de Deus. O próprio Kant (2005, p. 452) cita o caso exemplar do triangulo: "Demonstrar um triangulo e suprimir seus três lados é contraditório”. Mas para Kant (2005), daí não se seguiria que algo como um triangulo exista de fato também na realidade, do contrário, seria uma tautologia. “(...) o conceito de um ser 
absolutamente necessário é um conceito puro da razão, ou seja, uma simples ideia, cuja realidade objetiva está ainda longe de ser provada (...)”(KANT, 2005, P.450).

Veja-se mais, se se tomar o conceito Deus (sujeito), necessariamente segue a existência (predicado), porém, contrariamente, do mesmo modo, se se tirar o mesmo conceito Deus (sujeito), cai por terra também sua existência (predicado). Isto é, a existência como termo (predicado) que deve acompanhar a ideia de Deus, é apenas uma necessidade lógica e não existencial. Seria, por exemplo, o caso do conceito de triangulo: se se pensar o conceito de triangulo, automaticamente seus predicados, seus três lados, o acompanham. Ou seja, ao se pensar num triangulo, é legitimo pensar-se também nos lados que o compõe. Mas, qual a necessidade de que exista realmente um triangulo? A necessidade das partes do triangulo no seu conceito é puramente lógica, como num juízo qualquer. Poderia replicar-se, então, se não haveria contradição em dizer que Deus é perfeitíssimo, incluído neste conceito, sua existência e, ao mesmo tempo negá-lo como ser existente. Para Kant (2005), não há nenhuma contradição lógica. Só haveria contradição se concebêssemos Deus sem o predicado da existência a ele inerente, ou seja, somente se ele existisse na realidade sem o mesmo predicado da existência. Mas, dizer que Deus não existe, no máximo se está a dizer que o predicado que lhe acompanha, não existe também juntamente com ele:

Deus é todo-poderoso, eis um juízo necessário. A onipotência não pode ser anulada, se puserdes uma divindade, isto é, um ser infinito a cujo conceito aquele predicado é idêntico. Todavia, se disserdes que Deus não é, então nem a onipotência nem qualquer dos seus predicados são dados. Porque todos foram suprimidos junto com o sujeito e não há nesse pensamento nenhuma contradição. (KANT, 2005, P. 452).

Somente haveria contradição interna, no caso de se pensar um conceito sem o seu predicado, e não uma contradição externa, como se, ao dizer que não existe um conceito (Deus, triangulo etc.) na realidade, por ser a priori, fosse absurdo.

Do ponto de vista lógico, se eu coloco o sujeito 'triângulo' necessariamente se seguem os 'três ângulos'. Agora, do ponto de vista dos objetos, essa necessidade é condicionada à existência real do sujeito da sentença. Se existir um triangulo, então necessariamente existem três ângulos. Em analogia, se existir um Deus, então ele existe necessariamente (MANDELI, 2013, p. 40).

Uma tréplica a crítica de Kant (2005) poderia ser feita a partir do próprio núcleo do argumento ontológico e que o próprio Anselmo já teria se referido em sua resposta a objeção feita por seu contemporâneo e discípulo Gaunilo². Trata-se de se buscar comparar o conceito Deus necessário com outras formas, o que faz Gaunilo e Kant (2005) de algum modo também. O que Gaunilo teria dito é que se o argumento de Anselmo estiver certo em partir-se do conceito para deduzir sua existência real, então, pensar uma ilha perfeita faz dela uma ilha existente de

\footnotetext{
${ }^{2}$ Gaunilo (994-1083) foi um monge beneditino nascido em Marmotiers. Contra o argumento ontológico de Santo
} Anselmo, escreveu o Liber pro insipiente ao qual respondeu Anselmo com Liber apologéticus. 
fato. No caso de Gaunilo, Anselmo respondeu que aquele, ao comparar uma ilha necessária com Deus necessário, querendo com isso dizer que se se pensa uma ilha perfeitamente necessária e existente não faz que ela exista de fato e necessariamente, valendo o mesmo para Deus, não seria uma boa comparação, seria, portanto, uma analogia inadequada.

A objeção a essa questão colocada por Kant (2005), fora trazida por Mandele (2013) a partir de Malcolm (1960). Segundo o autor, comparar-se Deus com algo como triangulo, se é legitimo para os termos de uma explicação, não o é para termos de proposições do tipo "1 Se existe um triângulo (e é possível que não exista) então existem três ângulos. 2 Se existe um Deus (e é possível que não exista) então ele existe de forma necessária”. Não se poderia partir a priori da existência de Deus como existência contingente em comparação com outro ser, pois, a característica que the acompanha enquanto atributo seria a necessidade e não a contingência. Além disso, em consequência, para o mesmo autor, falar em existência necessária e em existência possível seria contraditório. Mandeli chama atenção para o fato de que:

\begin{abstract}
Se pensarmos em Deus em conexão com qualquer uma dessas situações, já não estaríamos lidando, ao menos prima facie, com o conceito adequado da divindade. A conclusão é que ou Deus existe de forma necessária, ou Deus não existe de forma necessária, ou, dito de outro modo: ou Deus é um possível-necessário ou ele é impossível. Não pode ser, como Kant estaria pensando, um possível-contingente (MANDELI, 2013, p. 40).
\end{abstract}

Mandeli (2013) parte desse ponto, que seria uma objeção de Malcolm (1960) feita a Kant, para defender que, se por um lado se tomar Deus como caso exclusivo em que sendo ele não existente, cria uma contradição, por outro seria possível identificar uma contradição interna tomando a própria proposição "Deus existe" em si mesma, a partir da distinção entre proposições analítica e sintética. Mandeli cita a seguinte passagem da crítica:

\footnotetext{
Cometestes já uma contradição ao introduzirdes no conceito de uma coisa, que queríeis pensar unicamente segundo a sua possibilidade, seja sob que nome oculto for, o conceito de sua existência. [...] Faço-vos uma pergunta sobre a seguinte proposição: esta ou aquela coisa (que vos concedo como possível, seja qual for) existe. Esta proposição é analítica ou sintética? (MANDELI, 2013, p. 41-42).
}

Proposições analíticas são aquelas em que o predicado B está contido no sujeito A, de modo que aquilo que o predicado diz pode se saber por análise. Nas proposições sintéticas o predicado B acrescenta uma informação ao sujeito A que não estava contida neste. Reale exemplifica melhor este ponto quando explica que:

(...) um juízo é 'analítico', como quando, por exemplo, digo que 'todo corpo é extenso'. O conceito de 'extensão', com efeito, é sinônimo de 'corporeidade' e, assim, quando digo todo 'corpo é extenso' nada mais faço que explicar e explicitar aquilo que se entende por 'corpo' (...). Quando digo 'todo corpo é pesado' pronuncio um juízo sintético, porque o conceito de 'pesado' não pode ser extraído por pura análise do conceito de 'corpo' (...) (REALE, 1990, p. 882) . 
Desse modo, segundo mandele (2013), para Kant (2005) ou a proposição "Deus existe" é sintética, o que não seria o caso, pois, o argumento ontológico parte e se fundamenta no fato de que tal proposição é a priori. Ou então a mesma proposição "Deus existe" é analítica, o que é o caso do argumento ontológico. Aceitando-se tal fato, o argumento se esbarra numa contradição interna.

Como dito (...), proposições analíticas, por definição, não acrescentam nada 'novo' ao conceito, pois apenas tornam evidentes os conceitos parciais, as notas características, que já estão pensadas no sujeito. Se 'existência' é uma nota característica do conceito 'Deus', obviamente ao dizer que Deus existe não introduzimos alguma nota característica nova no conceito, apenas evidenciamos algo que já estava pensado (...) (MANDELI, 2013, p. 44-45).

Por consequência, a proposição-base do argumento ontológico "Deus existe" que garantiria, segundo seus defensores, uma base evidente, se mostra segundo as observações de Kant, insuficientes para uma defesa da existência de Deus. Porém, mais uma vez cabe se perguntar se Anselmo quereria mostrar algo além do que, para ele o próprio argumento já mostra por si só.

\section{Considerações finais}

Não se pode ignorar que Kant pretendera questionar as bases da metafisica tradicional, sua legitimidade e pretensão à ciência, a luz da razão. Sua crítica tivera por consequência pôr em xeque conceitos como Deus, Alma, Felicidade. Anselmo, apesar de se valer da dialética, não via a razão como ponto de chegada, como campo exterior ao da fé, como se tivesse que prestar contas àquela, mas, via na razão, instância natural de reflexão sobre aquilo que, pela fé, já acreditava, a saber, Deus. Apesar de outros filósofos, como Descartes, que acolheu o argumento ontológico, ter vivido antes de Kant, (e assim se poderia ser tentado a dizer que o argumento ontológico nasceu, desenvolveu-se na história da filosofia e por fim, perdeu força), não se conclui que o argumento ontológico de Anselmo tenha perdido sua vivacidade. Os próprios autores citados confirmam tal fato a importância do mesmo.

Ainda atualmente, tanto o argumento de Anselmo como as objeções de Kant bem como a partir de dele têm parte na filosofia. Mais ainda, o próprio Kant, filósofo da modernidade dedicou algumas páginas de sua crítica ao discutir o argumento, o que em si já mostra sua importância. Se por um lado, Anselmo, despeito da crítica Kantiana a partir dos conceitos de sintético e analítico, não pretendera acrescentar algo a proposição do argumento, mas, sim partir dele como uma proposição razoável e coerente. Por outro, porém, Kant manteve sua atenção aos limites lógicos dos termos e proposições, o que também de modo algum pode servir como justificativa para afirmar que se referiu apenas a forma e não ao conteúdo do argumento. 


\section{REFERÊNCIAS}

CANTUÁRIA, Anselmo de. Proslógio. In: Os Pensadores. São Paulo: Abril Cultural,1973.

DESCARTES, René. Meditações Metafísicas. In: Os Pensadores. São Paulo: Abril Cultural,1990.

IMMANUEL, Kant. Crítica da Razão Pura. São Paulo: Editora Martin Claret, 2005.

MANDELI, Alison Vander. Comentários a crítica de Kant ao argumento ontológico. In: TONETTO, Milene Consenso; PINZANE, Alessandro (Orgs). Investigações kantianas II: Novas Vozes. Florianópoles: NEFIPO, 2013.

REALE, Giovanni. História da Filosofia: Antiguidade e Idade Média. $6^{a}$ Edição. São Paulo: Paulus, 1990.

REALE, Giovanni. História da Filosofia: Do Humanismo a Kant. $6^{\text {a }}$ Edição. São Paulo: Paulus, 1990.

VASCONCELLOS, Manoel. Filosofia Medieval: Uma Breve Introdução. São Paulo: NEPFIL, online, 2014: (Série Dissertatio-Incipiens. 